\title{
MORINGA OLEIFERASEBAGAI MAKANAN PENDAMPING ASI PADA BALITA STUNTING
}

Urwatil Wusqa Abidin', Andi Liliandriani ${ }^{2}$

Departemen Kesehatan Masyarakat, Universitas Al Asyariah Mandar

J1. Budi Utomo No.2 Manding, Kecamatan Polewali, Kabupaten Polewali Mandar, Provinsi Sulawesi Barat, Indonesia

\section{Article Info}

Article history:

Received Des 22,2020

Revised Feb 24, 2021

Revised Apr 23, 2021

Accepted Mei 25, 2021

\section{Keywords:}

Moringa Leaves

Moringa Oleifera

Toddler, Stunting

Complementary food for Asi

\begin{abstract}
Specific nutrition intervention efforts for short children under five are focused on the 1,000 First Day of Life (HPK) group. Consuming Moringa Oliferadi Polewali Mandar Regency is one of the efforts taken to accelerate the growth and development of toddlers because it is found in abundance of nutrients, such as: vitamin A, vitamin $C$, calcium, and iron. This research is expected to be an alternative for families with stunting toddlers in order to provide adequate nutritional intake by utilizing Moringa Olifera. This research uses a Quasi Experimental design, which is an experiment that has treatment, impact measurement, experimental units but does not use random assignments to create comparisons. in order to infer changes caused by treatment. The design used was one group pre test and post test design, which is a study by comparing the nutritional status of toddlers before the intervention and after the intervention. The results showed that the Sig. (2-tailed) both variables equal to 0.000. This value is <0.05, so it can be concluded that there is an effect of giving Moringa Oliferar powder on body weight (BW) and height (TB) of toddlers. Because of this, giving Moringa Olifera powder, can increase $B W$ and $T B$ in toddlers.
\end{abstract}

Corresponding Author:

Urwatil Wusqa Abidin

Department of Public health,

Al Asyariah Mandar University,

Budi Utomo No.2, Polewali Mandar Regency, West Sulawesi, Indonesia

Journal homepage: https://journal.lppm-unasman.ac.id/index.php/jikm/index 


\section{PENDAHULUAN}

Stunting merupakan salah satu dari masalah gizi pada anak yang berdampak buruk terhadap kualitas hidup dalam mencapai titik tumbuh kembang yang optimal sesuai potensi genetiknya Stunting dapat menghambat proses tumbuh kembang pada balita. Chilhood stuntingatau tubuh pendek pada masa anak-anak merupakan akibat kekurangan gizi kronis atau kegagalan pertumbuhan pada masa lalu dan digunakan sebagai indikator jangka panjang untuk gizi kurang pada anak [1]. Defisit pertumbuhan linear ini karena akumulasi dari 1.000 hari pertama kehidupan yang tidak optimal. Adapun indikator yang digunakan untuk mengidentifikasi balita stunting yaitu berdasarkan indeks Tinggi Badan menurut Umur (TB/U), menurut standar WHO child growth standart dengan kriteria stunting jika nilai z-score TB/U < -2 Standar Deviasi (SD) [2].

Pemberian makanan pendamping dengan kecukupan gizi pada masa balita sangat menunjang tumbuh kembangnya. Makanan pendamping ASI dapat berupa bubur pabrikan atau dibuat sendiri dengan menambahkan zat-zat gizi lain. Konsumsi makanan pendamping yang telah dicampur dengan suplemen mikronutrien terbukti dapat menambah bobot dan ukuran tubuh anak, selain itu terdapat banyak penelitian bahwa suplementasi dapat meningkatkan perkembangan kognitif anak [5].

Moringa Oleifera berhasil digunakan untuk mengatasi mal nutrisi pada anak-anak. Pada anak-anak menunjukkan kenaikan berat badan yang signifikan bila mengkonsumsi daun kelor yang ditambahkan pada makanannya. Mengkonsumsi daun Moringa Oleifera merupakan salah satu alternative untuk menanggulangi kasus kekurangan gizi di Indonesia. Pentingnya zat gizi Moringa Oleifera untuk pertumbuhan linear anak terutama yang masih dalam masa pertumbuhan menjadi dasar peneliti melakukan penelitian untuk mengetahui apakah ada pengaruh moringa oleifera (kelor)sebagai MP ASI pada balita stunting [6].

Salah satu upaya yang ditempuh untuk mempercepat pertumbuhan dan perkembangan balita adalah dengan memperkaya makanan pendampingnya dengan daun Moringa Oleifera (MO) atau kelor. Moringa Oleifera berhasil digunakan untuk mengatasi mal nutrisi pada anak-anak. Pada anak-anak menunjukkan kenaikan berat badan yang signifikan bila mengkonsumsi daun kelor yang ditambahkan pada makanannya. Mengkonsumsi daun Moringa Oleifera diharapkan alternative untuk menanggulangi kasus stunting di Polewali Mandar. 
Menurut UNICEF, WHO dan World Bank 2017 menunjukkan bahwa stunting diduduki oleh Negara India yang merupakan Negara pertama yang menjadi pusat perhatian bagi masyarakat yang mengalami stunting terbesar sedangkan Negara Indonesia berada diurutan ke-4 dengan masalah Stunting. Prevalensi stunting di Indonesia lebih tinggi daripada negara-negara lain di Asia Tenggara, seperti Myanmar (35\%), Vietnam (23\%), dan Thailand (16\%) Angka prevalensi stuntingnasional Indonesia tergolong dalam kategori berat dimana 14 provinsi di Indonesia tergolong kategori berat, dan sebanyak 15 provinsi lainnya tergolong kategori serius. Tercatat 20 provinsi yang angka prevalensinya di atas prevalensi nasional. Salah satunya adalah Provinsi Sulawesi Barat yang berada di urutan kedua tertinggi setelah Provinsi Nusa Tenggara Timur [3].

Provinsi Sulawesi Barat, tercatat prevalensi status gizi balita stunting berdasarkan TB/U sebesar 48,0\% terdiri dari sangat pendek dan pendek masing-masing adalah 22,3\% dan 25,7\%. Salah satu kabupaten yang ada di Sulawesi Barat yaitu Polewali Mandar yang menempati urutan kedua balita sangat pendek setelah kabupaten Majene [4].

Mapilli merupakan salah satu kecamatan yang ada di Polewali Mandar yang memiliki jumlah anak stunting sebesar 104 anak (34,67\%). Selama ini masyarakat Kecamatan Mapilli tidak mengetahui manfaat daun kelor bagi kesehatan. Masyarakat memanfaatkan daun kelor sebagai pakan ternak dan digunakan sebagai bahan untuk memandikan orang yang terkena guna-guna atau santet. Oleh sebab itu masyarakat kurang memanfaatkan daun kelor terutama sebagai bahan Makanan Pendamping ASI.

Jika dibandingkan dengan data sebelumnya ditahun 2017, jumlah anak dengan status gizi stunting di wilayah Puskesmas Mapilli mengalami kenaikan yang cukup drastis. Dari total anak stunting sebanyak 54 orang $(18,0 \%)$ di tahun 2018 mengalami kenaikan yang cukup besar pada tahun selanjutnya (2018) yakni sebanyak 104 anak (34,67\%). Hal inilah yang kemudian menjadi alasan penelitian pada kali ini. Kenaikan yang signifikan pada jumlah anak stunting di wilayah Puskesmas Mapilli membuat peneliti tertarik melakukan penelitian tentang Moringa Oleiferasebagai Makanan Pendamping ASI pada Balita Stunting diwilayah kerja puskesmas mapilli, Kecamatan Mapilli Kabupaten polewali mandar untuk memberikan referensi kepada petugas kesehatan dan ibu balita mengenai manfaat dan pengaruh moringa oleifera pada TB dan BB balita stunting. 
e-ISSN: 2541-4542

\section{METODE PENELITIAN}

\section{Jenis dan Desain Penelitian}

Desain Quasi Experimen (The one group pretest-posttest design)

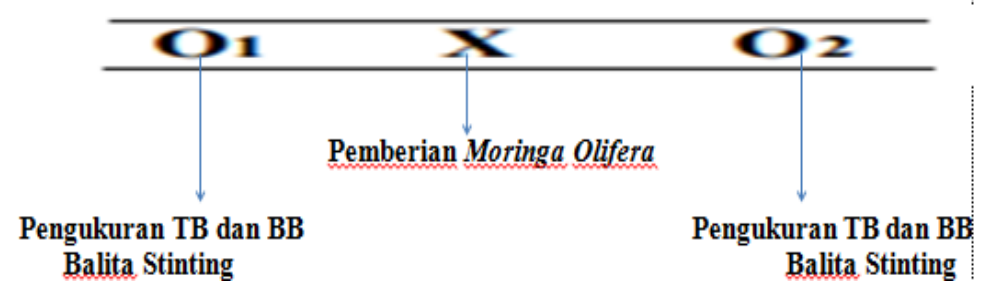

\section{Gambar 3.1 Desain Quasi Experimen}

Sumber : Dicky Hastjarjo. (2008). Ringkasan buku Cook \& Campbell. (1979).

QuasiExperimentation: Design \& Analysis Issues for Field Settings. Houghton

\section{Mifflin Co.}

Keterangan :
$\mathbf{X} \quad$ : Pemberian perlakuan
O1 : Pengukuran pretest
O2 : Pengukuran posttest

\section{Teknik pengambilan sampel}

penentuan sampel menggunakan metode accidental sampling yaitu siapa saja yang kebetulan bertemu dengan peneliti dilokasi penelitian dan dianggap cocok dengan karakteristik sampel yang ditentukan akan dijadikan sampel, berdasarkan:

\section{Kriteria Inklusi:}

Balita berumur $6-12$ bulan dengan z-score TB/U < -2 Standar Variable independen dalam penelitian ini adalah pemberian daun kelor pada balita. Pemberian daun kelor dilakukan selama 14 hari dengan memberikan serbuk kelor sebanyak 10 gram/hari kemudian dilakukan pengukuran Tinggi Badan dan Berat Badan. Variable dependen dalam penelitian ini adalah Tinggi Badan dan Berat Badan Balita Stunting.

Populasi dalam penelitian ini adalah semua balita stunting yang ada di Kecamatan Mapilli sebanyak 104 anak balita stunting. Jumlah sampel yang digunakan dalam penelitian ini sebanyak 18 responden. responden dalam penelitian ini adalah balita dengan Z-Score <2SD dan yang memenuhi kriteria inklusi. Uji statistik yang digunakan adalah Wilcoxon 
e-ISSN: $2541-4542$

\section{Bahan dan alat Penelitian}

Pengukuran Berat Badan menggunakan alat Timbangan dan untuk pengukuran Tinggi Badan menggunakan alat Microtoise. Pemberian Moringa Olifera (Daun Kelor) dilaksanakan selama 14 hari dengan memberikan serbuk kelor pada makanan yang akan diberikan kepada balitasebagai MP ASI sebanyak 10 gram/hari.

\section{Pengumpulan data}

Metode pengumpulan data yang digunakan oleh peneliti adalah :

1. Metode Observasi

Observasi dilakukan oleh peneliti untuk mendapatkan data dan informasi berkaitan dengan objek dan lokasi penelitian.

2. Penelitian Kepustakaan

Penelitian kepustakaan dilakukan dengan cara mempelajari, mendalami, dan mengutip dan teori-teori atau konsep-konsep dari berbagai literatur, dan hasil karya tulis yang relevan dengan topik penelitian

3. Hasil Pengukuran TB dan BB

Metode pengumpulan data juga bersumber dari hasil pengukuran TB dan BB, dimana setiap hasil pengukuran akan langsung didokumentasikan

\section{HASIL DAN PEMBAHASAN}

Hasil pengukuran BB dan TB Sebelum dan Setalah Pemberian serbuk Moringa Oleifera sebanyak $10 \mathrm{gr} /$ hari selama 14 hari sebagai berikut :

Tabel 1. Hasil Pengukuran Berat Badan Sebelum dan Setelah Perlakuan

\begin{tabular}{clcc}
\hline \hline & & BB SEBELUM & BB SETELAH \\
NO & NAMA & $\begin{array}{c}\text { PERLAKUAN } \\
(\mathbf{K g})\end{array}$ & $\begin{array}{c}\text { PERLAKUAN } \\
(\mathbf{K g})\end{array}$ \\
\hline \hline 1 & Rahman Hafis & 10,7 & 11,8 \\
2 & Alpin & 11,7 & 11,9 \\
3 & Naura Azzahra & 9,2 & 9,9 \\
4 & Muh Matar Ismail & 7 & 7,6 \\
5 & Nurul Berlian & 7,9 & 9,5 \\
\hline \hline
\end{tabular}




\begin{tabular}{llcc}
\hline \hline NO & \multicolumn{1}{c}{ NAMA } & $\begin{array}{c}\text { BB SEBELUM } \\
\text { PERLAKUAN } \\
(\mathbf{K g})\end{array}$ & $\begin{array}{c}\text { BB SETELAH } \\
\text { PERLAKUAN } \\
(\text { Kg })\end{array}$ \\
\hline \hline 6 & Muh. Fajar & 12,3 & 12,4 \\
7 & Yasmin Syarifah & 10,1 & 10,6 \\
8 & Nur Asisah A & 7,2 & 7,8 \\
9 & Nur Fadilah & 13 & 13,8 \\
10 & Alfian & 11,4 & 11,7 \\
11 & Muh. Fildan & 10,5 & 11,5 \\
12 & Fahmi & 11,6 & 12,2 \\
13 & Alifa Khairunnisa & 10 & 11,3 \\
14 & Andini & 12 & 12,8 \\
15 & Muh. Rusdi & 10,6 & 11,5 \\
16 & Fahmi Anwar & 11 & 11,9 \\
17 & Muh Ramadhan & 8,6 & 9,3 \\
18 & Muh. Fikar & 7,1 & 7,3 \\
\hline \hline
\end{tabular}

Sumber Data: Data Primer

Berdasarkan tabel 1.1 Diatas dapat dilihat bahwa semua responden mengalami kenaikan berat badan setelah diberikan perlakukan berupa pemberian serbuk moringa oleifera selama 14 hari dengan rata-rata berat badan sebelum perlakuan sebesar 10,11 Kg dan ratarata berat badan setelah perlakuan sebesar $10,82 \mathrm{Kg}$ sehingga rata2 kenaikan berat badan responden sebesar $0,71 \mathrm{Kg}(3,42 \%)$. 
Hasil Pengukuran Berat Badan sebelum dan setelah pemberian Moringa Oliefera Di Kec. Mapilli

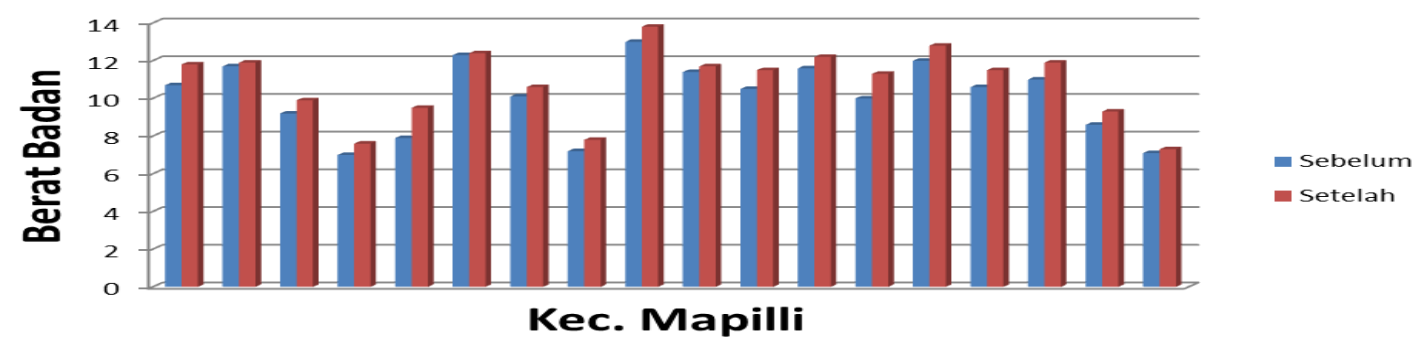

Gambar 1. Menunjukan bahwa, secara keseluruhan Berat Badan (BB) balita mengalami kenaikan $(3,42 \%)$

Gambar 1. menunjukan bahwa minimum Berat Badan (BB) seluruh sampel berada pada angka 7,00 dan pada nilai maksimum berada pada angka 13,00 namun, setelah diberikan perlakuan, didapatkan hasil minimum 7,30 dan hasil maksimum 13,80.

Tabel 2. Hasil Pengukuran Tinggi Badan Sebelum dan Setelah Perlakuan

\begin{tabular}{clcc}
\hline \hline NO & \multicolumn{1}{c}{ NAMA } & $\begin{array}{c}\text { TB SEBELUM } \\
\text { PERLAKUAN } \\
(\mathbf{c m})\end{array}$ & $\begin{array}{c}\text { TB SETELAH } \\
\text { PERLAKUAN }\end{array}$ \\
\hline \hline 1 & Rahman Hafis & 92 & 96,5 \\
2 & Alpin & 85,7 & 87,5 \\
3 & Naura Azzahra & 77 & 77,5 \\
4 & Muh Matar Ismail & 74 & 75 \\
5 & Nurul Berlian & 70 & 73 \\
6 & Muh. Fajar & 88 & 89,5 \\
7 & Yasmin Syarifah & 81 & 83,5 \\
8 & Nur Asisah A & 67 & 72 \\
9 & Nur Fadilah & 91 & 94 \\
10 & Alfian & 88 & 95 \\
11 & Muh. Fildan & 81,5 & 84,5 \\
12 & Fahmi & 87 & 88 \\
\hline \hline
\end{tabular}




\begin{tabular}{clcc}
\hline \hline 13 & Alifa Khairunnisa & 76 & 76,5 \\
14 & Andini & 97 & 97,5 \\
15 & Muh. Rusdi & 81 & 89,5 \\
16 & Fahmi Anwar & 88 & 91,3 \\
17 & Muh Ramadhan & 75 & 75 \\
18 & Muh. Fikar & 64 & 70,6 \\
\hline \hline
\end{tabular}

Sumber Data: Data Primer

Berdasarkan tabel 1.2 Diatas dapat dilihat bahwa 17 responden mengalami kenaikan Tinggi badan dan 1 orang responden tidak mengalami kenaikan tinggi badan. Rata-rata Tinggi badan sebelum perlakuan sebesar $81,29 \mathrm{~cm}$ dan rata-rata tinggi badan setelah perlakuan sebesar 84,24 cm sehingga rata-rata kenaikan tinggi badan responden sebesar $2,96 \mathrm{~cm}(0,02 \%)$.

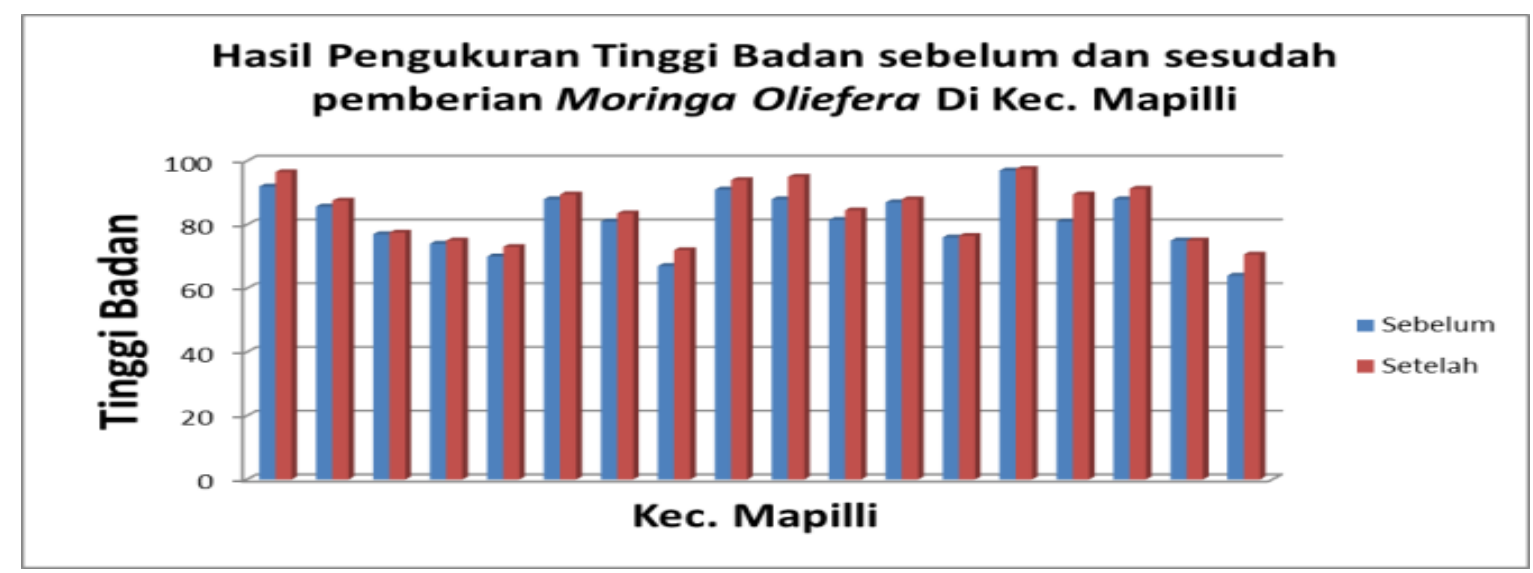

Gambar 2. Menunjukan bahwa, mayoritas data Tinggi Badan (TB) di atas mengelami kenaikan, kecuali 1 orang Tinggi Badannya (TB) tetap.

Gambar 2. diatas menunjukan angka minimum Tinggi Badan (TB) sebelum diberikan perlakuan yakni sebesar 64,00 dan nilai maksimum sebesar 97,00 mengalami kenaikan setelah diberikan perlakuan menjadi nilai minimum 70,60 serta nilai maksimum sebesar 97,50.

Pemberian intervensi dengan daun kelor secara jelas memberikan nilai yang positif terhadap kenaikan Berat Badan (BB) dan Tinggi Badan (TB). Hal tersebut dibuktikan dengan adanya perbedaan secara statistik yang bermakna Berat Badan (BB) dan Tinggi 
Badan (TB) balita antara sebelum dan sesudah diberikan tambahan bubuk Moringa Olifera terhadap Makanan Pendamping ASI (MP-ASI).

Berdasarkanhasilpenelitian,rata-rata Berat Badan (BB)sebelum diberikan perlakuanyaitu sebesar 10,11 dan sesudah perlakuan diperoleh rata-rata 10,82. Sedangkanuntuk Tinggi Badan (TB)sebelumperlakuandiperoleh rata-rata 81,29 dan .setelah dilakukan perlakuan diperoleh rata-rata 84,24.

Jika hasil intervensi sebelum dan sesudah diberikan perlakuan dikorelasikan, maka hasilnya dapat dilihat sebagai berikut:

Tabel 3. Nilai Korelasi BB dan TB

\begin{tabular}{lcll}
\hline & N & Correlation & Sig \\
\hline BB Sebelum \& & 18 & 0,978 & 0,000 \\
$\begin{array}{l}\text { Sesudah Perlakuan } \\
\text { TB Sebelum \& }\end{array}$ & 18 & 0,963 & 0,000 \\
Sesudah Perlakuan & & & \\
\hline
\end{tabular}

Tabel 1. menunjukan bahwa nilai korelasi antara Berat Badan (BB) sebelum dan sesudah perlakuan adalah 0,978. Serta korelasi antara Tinggi Badan (TB) sebelum dan sesudah perlakuan adalah 0,96. Hal tersebut dapat dikatakan bahwa hubungan data perlakuan Berat Badan (BB) dan Tinggi Badan (TB) sebelum dan sesudah yakni kuat dan positif.

Tabel 4. Hasil Uji Paired T-Test

\begin{tabular}{lll}
\hline & Mean & $\begin{array}{l}\text { Sig. } \\
\text { (2-tailed) }\end{array}$ \\
\hline BB Sebelum \& & 0,71667 & 0,000 \\
Sesudah Perlakuan & & \\
TB Sebelum \& & $-2,95556$ & 0,000 \\
Sesudah Perlakuan & & \\
\hline
\end{tabular}

Berdasarkan Tabel 2. Diketahui bahwa nilai Sig. (2-tailed) kedua variabel sebesar Jurnal Kesehatan Masyarakat, Vol. 07, No. 1, 2021: 40-51 
e-ISSN: 2541-4542

0,000. Nilai ini < 0,05, sehingga dapat disimpulkan bahwa terdapat pengaruh pemberian serbuk Moringa Oliferaterhadap Berat Badan (BB) dan Tinggi Badan (TB) balita. Oleh karena hal tersebut, pemberian bubuk Moringa Olifera, dapat meningkatkan BB dan TB pada balita.

Sedangkan Mean untuk Berat Badan (BB) bernilai positif, yakni 0,71667 serta Mean untuk Tinggi Badan (TB) yakni -2,95556. Hal ini memberikan arti bahwa terjadi kecenderungan peningkatan $\mathrm{BB}$ dan $\mathrm{TB}$ sebelum dan sesudah diberikan perlakuan pemberian bubuk Moringa Olifera. Adapun rata-rata peningkatann BB adalah 0,71 $(3,42 \%)$ dan TB adalah $-2,96(0,02 \%)$.

Sudah banyak penelitian yang mengatakan bahwa konsumsi bahan makanan dalam bentuk suplemen (suplementasi) dapat menigkatkan perkembangan kognitif anak. Salah satu hal yang dapat dilakukan guna mempercepat tumbuh kembang balita diantaranya dengan cara meningkatkan kualitas makanan pendamping ASI . Salah satunya dengan pemanfaatan produk lokal seperti bubukMoringa Olifera.

Penelitian ini seakan sejalan dengan penelitian yang dilakukakn oleh Rahayu dengan judul Peningkatan Status Gizi Balita Melalui Pemberian Daun Kelor (Moringa Oleifera) yang mana dari hasil penelitiannya menghasilkan sebuah kesimpulan bahwa pemberian daun kelor berpengaruh utuk meningkatkan status gizi balita berdasarkan IMT menurut umur balita. (2018).

Hal tersebut juga didukung oleh penelitian yang dilakukan oleh Muliawati dengan hasil penelitian yang menunjukan bahwa ekstrak Moringa Oleifera dapat meningkatkan tinggi badan sebesar $0,342 \mathrm{~cm}$.

\section{KESIMPULAN}

Dari hasil penelitian yang telah dilakukan, diperoleh hasil bahwa terdapat perbedaan Berat Badandan Tinggi Badan sebelum dan sesudah pemberian bubuk Moringa Olifera. Maka dengan demikian, perlu dilakukan kegiatan persuasif kepada kader dan ibu balita agar meningkatkan jumlah konsumsi daun kelor baik dalam wujud sayur-sayuran maupun dalam berbagai olahan seperti bubuk Moringa Olifera. 
e-ISSN: 2541-4542

\section{UCAPAN TERIMA KASIH}

Ucapan terimah kasih kepada semua pihak yang terlibat dalam penelitian ini khusunya kepada Direktorat Jendral Pendidikan Tinggi, Dines Kesehatan Kabupaten Polewali Mandar, Puskesmas Mapilli dan segenap masyarakat diwilayah penelitian atas batuannya selama penelitian dilaksanakan.

\section{DAFTAR RUJUKAN}

[1] Yusdarif, 2017. Determinan kejadian stunting pada balita usia 24-59 bulan di kelurahan rangas kecamatan banggae kabupaten majene tahun 2017. Universitas Islam Negeri Alauddin Makassar.

[2] Almatsier, Sunita. 2005. Prinsip Dasar Ilmu Gizi. Jakarta: PT. Gramedia Pustaka Utama.

[3] Riset Kesehatan Dasar (Riskesdas). 2013. Laporan Hasil Riset Kesehatan Dasar (Riskesdas) 2013. TNP2K, Kementerian Koordinator Bidang Pembangunan Manusia dan Kebudayaan, dan Kementerian PPN/ Bappenas 2018

[4] Dinas Kesehatan Kabupaten Polewali Mandar. 2018. Laporan Gizi Kabupaten Polewali Mandar. Dinkes Polewali Mandar : 2019

[5] Purwaningsih E. 2001. Pengaruh suplementasi seng dan besi terhadap pertumbuhan, perkembangan psikomotorik dan kognitif bayi : uji lapangan di Indramayu, Jawa Barat. Tesis pada Universitas Indonesia Jakarta: 2001.

[6] Zakaria,dkk. 2012. Penambahan Tepung Daun Kelor Pada Menu Makanan Sehari-hari Dalam Upaya Penanggulangan Gizi Kurang Pada Anak Balita. Jurnal Media Pangan dan Gizi vol.XIII, edisi 1 hal 44.

[7] World Health Organization. Standar Antropometri Penilaian Status Gizi Anak. Keputusan Menteri Kesehatan Republik Indonesia. Jakarta: WHO; 2006

[8 ]Adiningsih, Sri. 2010 Waspadai Gizi Balita Anda. Jakarta : Elex Media Komputindo.

[9 ]Allen and Gillespie, 2001. Stunting, Wasting, and Micronutrient Deficiency Disorders. https://www.ncbi.nlm.nih.gov/books/NBK11761/. Diakses 10 Agustus 2018.

[10] Sulistyoningsih. 2011. Gizi Untuk Kesehatan Ibu dan Anak. Yogyakarta: Graha Ilmu.

[11]Tri Budi Rhayu, dkk 2018. Peningkatan Status Gizi Balita Melalui Pemberian Daun Kelor. Jurnal Kesehatan Madani Medika, Vol 9 No 2 Desember 2018

[12] Rahayu, T. B., \& Nurindahsari, Y. A. W. (2018). Peningkatan Status Gizi Balita Melalui Pemberian Daun Kelor (Moringa Oleifera).Zakaria, T. A., Lestari, R., \& Hartono, R. (2013). Pemanfaatan Tepung Kelor (Moringa oleifera) dalam Formulasi Pembuatan Makanan Tambahan untuk Balita Gizi Kurang. Media Gizi Pangan, 15(1).

[13] Kuswanto, W. R. A. K. R., \& Widanti, Y. A. (2018). Penambahan puree daun kelor (moringa oleifera) dan puree pisang ambon untuk formula MPASI (Makanan Pendamping ASI). JITIPARI (Jurnal Ilmiah Teknologi dan Industri Pangan UNISRI), 3(1).

[14] Mardiana, A., Firdaus, F. N., Aziz, F. F., Birnanda, Y. E., Dewanti, R. A., \& Azizah, D. N. (2019). Pelatihan Pembuatan Buridor (Bubur Instan Daun Kelor) Sebagai MpAsi B2sa Di Desa Tanjung Kecamatan Mangli Kabupaten Jember. J-Dinamika: Jurnal Pengabdian Kepada Masyarakat, 4(1). 
[15]Pardosi, M.M (2019). Pengaruh Pemberian Cookies Dengan Penambahan Tepung Daun Kelor Terhadap Kenaikan Berat Badan Anak Gizi Kurang 12-59 Bulan di Wilayah Kerja Puskesmas Petumbukan

[16] Sihombing, M.A. (2019) Efektivitas Kapsul Ekstrak Daun Kelor Terhadap Kecukupan Asi pada Bayi Kurang dari 6 Bulan Ditinjau Dari Berat Badan Bayi Di Wilayah Kerja Puskesmas Sri Padang Kota Tebing Tinggi Tahun 2018Kusumawati, E., Rahardjo, S., \& Sari, H. P. (2015). Model pengendalian faktor risiko stunting pada anak bawah tiga tahun. Kesmas: National Public Health Journal, 9(3), 249-256.

[17] Muliawati, D., Sulistyawati, N., \& Utami, F. S. (2019, November). Manfaat Ekstrak Moringa Oleifera Terhadap Peningkatan Tinggi Badan Baita. In Prosiding Seminar Nasional: Pertemuan Ilmiah Tahunan Politeknik Kesehatan Karya Husada Yogyakarta (Vol. 1, No. 1, pp. 46-55).

[18] Rahayu, T. B., \& Nurindahsari, Y. A. W. (2018). Peningkatan Status Gizi Balita Melalui Pemberian Daun Kelor (Moringa Oleifera).

[19] Muliawati, D., \& Sulistyawati, N. (2019). Pemberian Ekstrak Moringa Oleifera Sebagai Upaya Preventif Kejadian Stunting Pada Balita. 